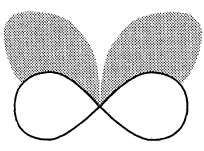

\title{
Vicariance or dispersal: the use of natural historical data to test competing hypotheses of disjunction on the Tyrrhenian coast
}

George F. Estabrook Professor of Botany, The University of Michigan, Ann Arbor, MI 48109-1048,USA. E-mail: estabrook@umich.edu

\begin{abstract}
Aim To illustrate the use of natural historical data to evaluate vicariance and dispersal as hypotheses competing to explain disjunct populations.
\end{abstract}

Location Nine disjunct areas on the margin of the Tyrrhenian basin of the Mediterranean Sea.

Methods First describe how each hypothesized mechanism might explain the observed morphological variation in the model species complex, Genista ephedroides (Fabaceae); then confront the hypotheses with natural historical data including geology, oxygen isotopes, palynology, macro-, micro- and nano-fossils, and sea level changes, and with the ecological tolerances of the model species complex.

Results Dispersal seems the more credible explanation.

Main conclusion Patterns of morphological (or other) variation among related disjunct taxa can fit both vicariance and dispersal hypotheses. However they can possibly be distinguished by considering natural historical data.

\section{Keywords}

Vicariance, dispersal, Genista, compatibility, Tyrrhenian, Pleistocene, natural history, Mediterranean.

\section{THE SPATIAL PATTERN OF THE MODEL SPECIES COMPLEX}

Taxa in the Genista ephedroides DC species complex are fruticose brooms that grow near the coast, and on islands near the coast of the southern Tyrrhenian Sea and near the Algerian coast. They tolerate especially well the intense seasonal heat and drought typical of the modern southern Mediterranean climate. The Sardinian populations survive brush fires that burn frequently there. De Candolle first described G. ephedroides in 1825 from a specimen collected in Sardinia. Spach (1845) in his revision of Genista placed it in the section Spartioides, whose centre of diversity is in North Africa and the Middle East. Taxa of the G. ephedroides complex are known from disjunct areas around the Tyrrhenian basin of the Mediterranean Sea: the Algerian coast; the coast, and islands near the coast, of Sardinia; the northern coast of Sicily and the islands nearby; the Neapolitan coast; and the Island of Ponza near the coast of central Italy.

Populations exhibit considerable morphological variation from one disjunct area to another, which has provoked a continuing controversy about their taxonomic status, as reviewed by De Marco et al. (1985). It is not the purpose of this report to engage that controversy; therefore these populations will be referred to here by the letters assigned to their place names in Table 1 . Figure 1 shows the location of these nine places.

De Marco et al. (1985) described the morphological variation among the populations in these disjunct areas. They measured 14 representative collections from each of the nine areas and for a large number of properties. For a given property, each area has 14 values of which the central eight were taken to represent its central range. For a given property, the nine central ranges were arranged in increasing order; whenever the central ranges of areas adjacent in this order did not overlap, a distinction was recognized between all the areas with smaller, and all the areas with larger, central ranges. These authors discuss their data-gathering and distinction-recognizing process in more detail. The result of their comparative study is that 16, among the many properties measured, emerged from this operational process, each the basis for one or two distinctions. Table 2 
Table I The names of the nine disjunct areas from which specimens of the G. ephedroides complex were taken for measurement and one hypothetical area determined by the analysis of the characters in Table 2. In the text and in Fig. 1, they are referenced by the letters a, $\mathrm{b}, \ldots, \mathrm{j}$. All areas are in Italy except area $\mathrm{g}$, which is in Algeria, and hypothetical area j, whose location, if it actually exists, is not certain.

a. Isola di Ponza

b. Marina d'Ascea

c. Pisciotta

d. Isola di Vulcano

e. Isola di Lipari

f. Isola di Salina

g. Yakouren (Algeria)

h. Isola di S. Antioco

i. Isola di S. Pietro

j. Hypothetical

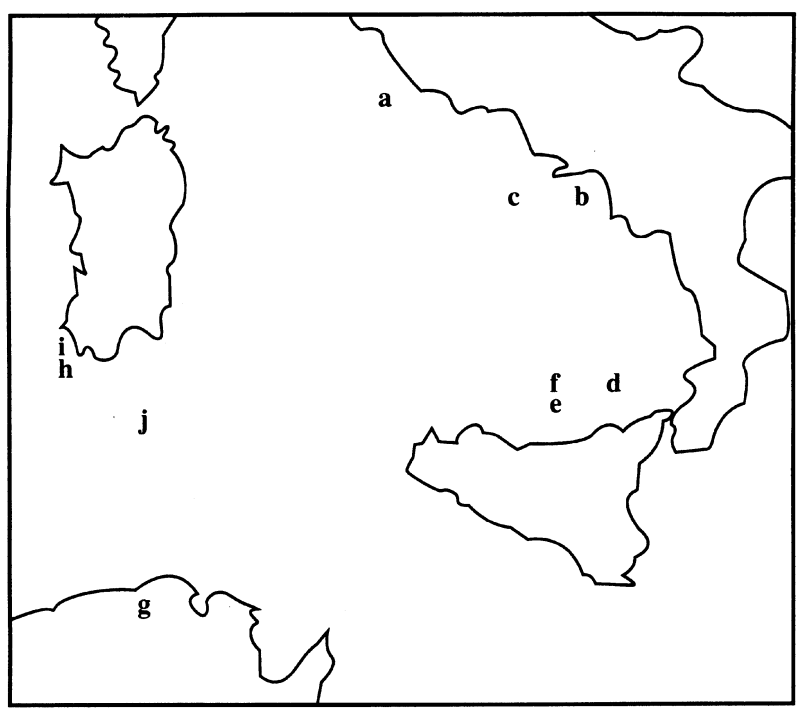

Figure I South Central Mediterranean Sea. The rectangle enclosing map represents an area $c .830 \mathrm{~km}$ wide and $750 \mathrm{~km}$ high. The locations of the nine disjunct areas of the G. ephedroides complex are shown with the letters $a, b, \ldots$, i. The location of hypothetical area $\mathrm{j}$ is somewhat arbitrary.

presents a brief description of these 16 bases for measurement and the populations/areas they distinguish. The present disjunct geographical distribution of G. ephedroides and the associated morphological patterns provoke speculation on the historical dynamics that produced them. The purpose of this report is to engage in this speculation.

\section{HYPOTHETICAL HISTORICAL MECHANISMS TO ACCOUNT FOR PATTERN}

Areas occupied by taxa in a species complex can come to be disjunct in two basic ways, which we call vicariance and dispersal. In vicariance, a single, originally widespread distribution becomes divided into disjunct areas. This could
Table 2 Sixteen characters of G. ephedroides.

(1) Branch structure

(A) Short and rigid

(B) Longer and more flexible

(h, i)

(2) Raceme structure

(A) Sparse, with fewer than 12 flowers

(B) Dense, with more than 12 flowers

(h, i)

$(a, b, c, d, e, f, g)$

(3) Length of calyx tube ( $\mathrm{mm})$
(A) $<1.8$
(B) From 2.0 to 2.2
(b, c, g, h, i)
(C) $>2.2$
$(e, f)$
$(\mathrm{a}, \mathrm{d})$

(4) Length of teeth on the lower calyx lip divided by the length of the lower calyx lip
(A) $>1 / 3$
(a, d, e, f, h, i)
(B) $<1 / 4$
$(\mathrm{b}, \mathrm{c}, \mathrm{g})$

(5) Upper calyx lip length divided by lower calyx lip length
(A) $<3 / 4$
(b, c, g, h, i)
(B) $>3 / 4$
$(\mathrm{a}, \mathrm{d}, \mathrm{e}, \mathrm{f})$

(6) Form of the teeth on the lower calyx lip
(A) Parallel, equal
(B) Divaricate, central longer
(a, d, e, f, h, i)
$(b, c, g)$

(7) Form of the teeth on the upper calyx lip
(A) Clearly acuminate
(a, d, e, f, h, i)
(B) Not (or only slightly) acuminate
(b, c, g)

(8) Length of fruit $(\mathrm{mm})$
(A) $<7.3$
(B) $7.5-10.0$
(C) $>10.0$
(b, c, g)
(d, e, f, h, i)
(a)

(9) Width of fruit $(\mathrm{mm})$
(A) $<3.4$
(B) $3.4-4.0$
$(\mathrm{b}, \mathrm{c})$
(C) $>4.3$
(g, h, i)
$(a, d, e, f)$
(10) Length of calyx (mm)
(A) $<3.8$
(h, i)
(B) $>3.8$
(a, b, c, d, e, f, g)

(11) Length of floral tube divided by the length of the calyx
(A) About 1/3
(B) $>1 / 3$ and $<2 / 5$
(b)
(C) $>2 / 5$
(c, g)
(a, d, e, f, h, i)

(12) Length of vessel $(\mathrm{mm})$
(A) $<6.7$
(B) $>6.7$
(b, c, g, h, i)
(a, d, e, f)

(13) Vessel length divided by vessel width
(A) $>1.0$
(B) $<1.0$
(a, d, e, f, h, i)
(b, c, g)

(14) Wing length (mm)
(A) $<6.5$
(B) $>6.5$
$(\mathrm{a}, \mathrm{d})$
(15) Pollen length $(\mu \mathrm{m})$
(A) $<24.5$
(a)
(B) From 24.5 to 27.5
(d, e, f, h, i)
(C) $>27.5$
(b, c, g)

(b, c, e, f, g, h, i)

(16) Pollen width $(\mu \mathrm{m})$
(A) $<21$
(a)
(B) $>21$
(b, c, d, e, f, g, h, i) 
happen by geological events such as the rising of mountain ranges or the breakup of land masses into separate islands or continents. Nelson \& Platnick (1981) offer this as a plausible explanation for disjunct distributions of higher taxa whose evolution has occurred over the past few to hundreds of millions of years during which such vicariance events have taken place. Vicariance could also happen over a shorter time span if an originally widespread population experienced in parts of its original range habitat deterioration or destruction, or invasion by superior competitors. As a consequence, it might disappear from those parts, leaving a disjunct distribution.

In dispersal, populations could have been founded in new areas, following dispersal from established populations in areas disjunct from them. Subsequently, some of these areas could have remained isolated from each other and dispersed propagules to found new populations in other disjunct areas, etc., creating a disjunct distribution.

\section{EVOLUTION DURING VICARIANCE CREATING DISJUNCT AREAS}

Because the Mediterranean Sea evaporates more water than flows into it from rivers and rain, its level is maintained by an inflow from the Atlantic Ocean through the Straits of Gibraltar. About $6 \mathrm{Myr}$ BP, the African plate apparently continued northward against the Iberian plate to close the Straits of Gibraltar. As a consequence, until about 5 Myr в when the Straits of Gibraltar reopened, the basin of the Mediterranean Sea was mostly dry land, with isolated lakes over the deepest trenches (Hsu, 1973, 1977, 1983). This million year period is known as the Messinian, when the Mediterranean basin was a salty desert or steppe with salttolerant taxa, such as those in the G. ephedroides complex.

Consider the possibility that the present populations in the nine disjunct areas are descendants of a single, nearly homogeneous population related to $G$. ephedroides that existed 5 Myr BP, during the Messinian when the Mediterranean was nearly dry, and the low land may have been covered by salt-, heat- and drought-tolerant vegetation. This population may have occupied a wide range that was reduced by the refilling of the Mediterranean basin, which could have left plants in their present disjunct areas. If the Mediterranean refilled rapidly, then the range of such a nearly homogeneous population would be fragmented rapidly, and the variation shown by the nine sampled sites would have evolved subsequently and simultaneously as the result of selection or drift operating independently on the isolated populations.

If the Mediterranean refilled more slowly, relative to the evolution of differences among the present disjunct populations, then at first Sardinia would have been isolated from the rest because the deepest trench is southeast of it. Separate evolutionary changes could have occurred in each of these two now isolated parts of the former contiguous population; their spread across the now filled trench would be prevented. Next, Sicily/Italy would separate from Algeria, because the sea bed separating them is not so deep, and subsequent evolutionary changes in Algeria would not be able to spread to Sicily/Italy. As the waters slowly rose, this process would continue. In general, an evolutionary change occurs within one continuous population bounded by barriers; selection (or possibly drift) passes this change uniformly throughout the contiguous population, but it is blocked by geographical barriers from being passed to other isolated populations; by the time a contiguous population is fragmented again, all its pieces have the evolutionary change.

The history of this process could be represented with a diagram in which all the populations/areas (including former continuous less fragmented ones) are represented by names. Arrows are drawn from the name of one that became divided to the names of the ones into which it was divided. These arrows are labelled with evolutionary changes that occur in each population, after it was divided from its former undivided population, and before it is subsequently divided again.

\section{A NECESSARY CONDITION}

Sometimes an evolutionary change enables us to distinguish some populations from others. For example, a change in the length/flexibility of branches (Table 2, character 1) distinguishes populations in areas $\mathrm{h}$ and $\mathrm{i}$, with short and rigid branches, from the rest, with longer and more flexible branches. Suppose an evolutionary change on which such a distinction is based evolved only once, and subsequently spread throughout the contiguous population in which it evolved before that population was fragmented again, and that subsequent to fragmentation no further evolutionary changes effecting that distinction occurred. Such a distinction would represent a barrier, with one of the two distinguished properties evolving and spreading in one of the fragments created by the barrier, after the barrier was erected and before that fragment was again fragmented by a subsequent barrier. Furthermore, such a distinction would still be apparent today among the disjunct populations being measured and compared.

Suppose we compared two different distinctions that evolved during vicariance as described above. For example, suppose that in addition to stem flexibility we also considered the teeth on the lower calyx lip (Table 2, character 6), which distinguishes populations in areas $\mathrm{b}, \mathrm{c}$ and $\mathrm{g}$, with unequal and divaricate teeth from the rest, with equal and parallel teeth. If in fact these two distinctions represented two barriers in the same historical vicariance process, then necessarily one distinction could divide populations in only one of the two groups distinguished by the other. Thus, 'only at most one group subdivided' is a necessary condition for two distinctions to be consistent with the same historical vicariance process, as represented by a particular arrow diagram.

Let us understand what it means to be a necessary condition. We can see that character 1 divides only one of the two groups distinguished by character 6 , i.e. the group with parallel teeth on the lower calyx lobe is divided into those with short stiff branches and those with long flexible 
branches, but the group with divaricate teeth on the lower calyx lobe is not divided because they all have long flexible branches. Because characters 1 and 6 as a pair satisfy the necessary condition, it is possible that they could both represent barriers in the same historical vicariance process; they are said to be compatible because they do not represent contradictory evidence for every historical vicariance process. We can also see that character 6 divides only one of the two groups distinguished by character 1 . Thus, the compatibility of a character pair, in the absence of additional evidence, does not indicate the direction (only the existence) of the arrows in the diagram. It is also possible for two characters to be compatible, but not to have evolved in the way described during a vicariance process. However, if a character pair did not satisfy the necessary condition, then we would know for sure that there could not be any historical vicariance process in which they both represented a barrier.

Although this necessary condition is based on unobserved historical processes, we need only data measured in present day to test and see if it is satisfied. Similar to the weight of scientific data in any argument, the test does not prove that any particular historical vicariance process actually took place, but if many different characters are all compatible with the same particular historical vicariance process, i.e. all pairs of them satisfy the necessary condition, then this lends weight of evidence and accrues to the plausibility of the hypothesized process. In the case of incompatible character pairs, it does prove that not both can correspond to barriers in the same vicariance process.

These concepts have been generalized to apply to characters with many states (properties) and to many characters at once, to discover suites of characters that are simultaneously compatible, i.e. consistent with a particular vicariance diagram (Estabrook \& Meacham, 1980; Estabrook, 1984, 1985; Meacham \& Estabrook, 1985). If many characters are simultaneously compatible they can determine a single particular vicariance diagram. If other explanations do not seem likely, then this diagram becomes a plausible interpretation. Although the existence of the vicariance events (the placements of the arrows) can be estimated in this way, their direction (which way the arrow points) cannot be inferred from the comparative data alone, without additional argument and data.

\section{THE NECESSARY CONDITION IS SATISFIED}

De Marco et al. (1985) show that all 16 characters of Table 2 are compatible with the vicariance diagram shown in Fig. 2. This is a remarkably surprising result. If the populations were rearranged at random across the distinctions, maintaining the numbers of areas with each property but permuting their identities, as if they had evolved independently in previously isolated populations, then the probability that all distinctions would be consistent with the same historical vicariance pattern would be vanishingly small (Meacham, 1981). The result is all the more remark-

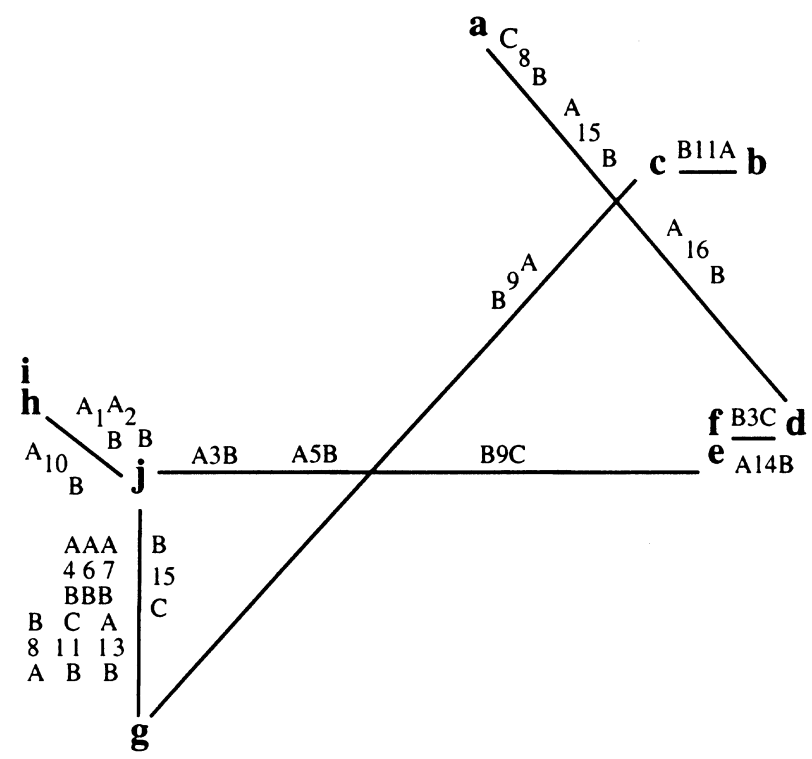

Figure 2 Diagram of the nine disjunct areas of the G. ephedroides complex named in Table 1, together with the hypothetical area $j$, showing historical contiguity with lines connecting contiguous areas. On each line are shown the evolutionary changes that would have occurred following the founding or isolation of an area by/from its historically contiguous neighbour. Numbers and capital letters are as in Table 2. Plants sampled in an area posses the property designated by the capital letter on its side of each character number. The placement of the letters $a, b, \ldots, j$ approximates their geographical placement in Fig. 1, with compromises to display more clearly evolutionary changes. The placement of hypothetical area $j$ is somewhat arbitrary.

able because of the objective manner in which De Marco recognized distinctions, and because all the distinctions he recognized in this manner were included. In Fig. 2, the diagram of historical contiguities, the placement of the area letters approximates their geographical locations shown in Fig. 1, with some compromise to show historical contiguity and morphological changes more clearly. The diagram determined by the compatibilities of the characters of Table 2 contains (and requires) a hypothetical area labelled $j$. Plants with the character states of area $j$ are no longer extant (if ever they were), so we cannot tell where area $j$ would have been. It has been placed arbitrarily in the southern Tyrrhenian sea, not to suggest that it is an island but to show the ambiguity of its position.

\section{EVOLUTION DURING COLONIZATION OF DISJUNCT AREAS}

Any time after ecological conditions became appropriate, populations of the G. ephedroides complex could have colonized their present disjunct areas by the establishment of founder populations following dispersal. Runemark (1970) has argued that if dispersal/founding events are relatively rare, founding populations are small and newly colonized areas have slightly different environments, then evolutionary 
change in a population following founding would be more likely than similar changes throughout the larger, long established area from which the founders came. Subject to slightly different selection in the new area, these small populations undergo some evolutionary change following founding but before expanding to fill a larger area. Of course with the passage of enough time, evolutionary change could also take place in the population in the long established area as well.

Let us suppose that a seed went out from area $\mathrm{x}$ and founded a population in area $\mathrm{y}$. Initially, plants in areas $\mathrm{x}$ and $y$ would be identical. But in the case described above, soon evolutionary change would occur and spread in the newly founded population in area y so that, with respect to what the character changed, plants in area y would become different from those in area $\mathrm{x}$. Suppose that, after this happened, a seed went out from the population in area $y$ and founded a population in area $\mathrm{z}$, the population in $\mathrm{z}$ would have the novelty that evolved in the population in area $y$ after its founding by the population in area $\mathrm{x}$, because that property was brought to the population in $\mathrm{z}$ by its founder from y. Soon after its founding from y, another novelty might evolve in the population in $\mathrm{z}$, and so on.

Suppose this founding process continues, with newly founded populations expanding into areas that remain isolated from each other, and novel properties of different characters evolving with each new founding. The history of this process could be represented with a founder diagram in which the areas are represented by names. An arrow is drawn from one area name to another if a propagule from the one founded the population in the other. On each arrow could be shown the changes that occurred in the newly founded population soon after the founding event represented by that arrow.

\section{THE NECESSARY CONDITION REVISITED}

If populations of the G. ephedroides complex were founded in disjunct areas in this way (with some plants that formerly exhibited some combinations of properties now possibly extinct), then distinctions based on novelties that evolved during the founding process described above would show patterns that were consistent with this process. Suppose that such a process actually occurred, and consider the name and arrow diagram that represents it. If you were to remove an arrow, then the diagram would fall into two internally connected pieces. The first piece, formerly at the head of the removed arrow, would contain the area whose colonization is represented by that arrow, plus all the areas subsequently colonized by descendants of plants in this area. The second piece, formerly at the tail of the removed arrow, would contain the area whence came the propagule of the colonization represented by that arrow, plus all the other areas not in the first piece. All the areas of the first piece would contain plants with the property that evolved during the founding event represented by the arrow, and none of the areas of the second piece would contain plants with that property. Thus, any property that evolved shortly after a founding event (as described above) enables us to distinguish two groups of areas: one whose plants have the original property of the founder and another whose plants have the newly evolved property. Such a distinction corresponds to the arrow in the founder diagram that divides the one group from the other.

Consider a second arrow in the founder diagram. If we remove it, then only at most one of the two groups of areas determined by the removal of the first arrow will be further divided into two groups. Therefore, if we consider two distinctions, a necessary condition that they both correspond to arrows in the same founder diagram is that the first distinction must divide at most one of the two groups distinguished by the second.

Apparently, the mechanics of testing characters to see if they can correspond to arrows in the same diagram of hypothesized historical process are the same whether vicariance or dispersal has been hypothesized. Characters that are compatible with the same vicariance diagram are always compatible with the same dispersal diagram and vice versa. In fact, the diagrams that the compatible characters determine are the same; we just interpret them differently. Thus, both vicariance and dispersal hypotheses predict that many of the evolved distinctions would be compatible with each other and thus consistent with the same diagram. If data do exhibit a high level of compatibility, then either vicariance or dispersal, or possibly a careful mixture of them, may explain the relationship between areas and the properties of related taxa that occur in them. If the data exhibit a low level of compatibility, then neither of these hypotheses is a very plausible explanation. For example, we would predict low levels of compatibility among the characters in Table 2 from the hypothesis that Mediterranean had filled rapidly, creating $5 \mathrm{Myr}$ в old disjunct areas from a widespread population in the G. ephedroides complex.

Thus, a high level of compatibility among characters does not by itself distinguish vicariance from dispersal explanations, both of which predict high levels of compatibility. To distinguish these hypotheses, we must must consider additional data and argument. Workers in a wide variety of scientific areas have been gathering data about natural history. We have already used some of them to describe the vicariance scenario in the Tyrrhenian basin following the Messinian. Together with high levels of character compatibility, such plausible scenarios based on natural history data can lend credence to hypotheses. But let us consider some more recent natural history.

\section{THE POST-MESSINIAN CLIMATE OF THE MEDITERRANEAN SEA SHORE}

The present Mediterranean climate is characterized by strong seasonality: half a year of cool, wet winter alternates with half a year of hot, dry summer. A distinct vegetation has evolved and assembled itself in the context of this climatic regime, varying predictably with altitude and, somewhat less so with latitude. Seasonal extremes are greater in the east than in the west, so there is also some predictable variation with longitude; but within the 
longitudinal confines of the Tyrrhenian basin this variation is slight. Elements of the vegetation are generally adapted to tolerate several months of hot drought every summer and to take advantage of the availability of water during the cooler, wetter winter. Recent work shows that vegetation bordering the Mediterranean Sea was not always like this.

During the Messinian, the Mediterranean Sea seems to have partially reflooded with fresh or brackish water from the east, and subsequently redesiccated, c. 8 times (Hsu, 1983). About 5 Myr BP, the Mediterranean Sea was completely refilled by the Atlantic Ocean, following a re-opening of the Straits of Gibraltar. For the next $2 \mathrm{Myr}$, until about 3.2 Myr вр, the climate in the north-western Mediterranean seems to have been subtropical, with little seasonal variation and wet warm summers. This is evident from oxygen isotope ratio data (Thunell \& Williams, 1983), pollen data (Suc, 1984) and macro fossils of subtropical plants from Northwestern Italy (Principi, 1942).

Pokras \& Mix (1987) have shown that arid conditions had already been established in North Africa as early as 3.9 Myr BP. The pollen data of Suc (1984) from South-east France shows the appearance about 3.2 Myr BP of species more tolerant of summer drought. About 2.3 Myr в extremely drought tolerant species entered the pollen record compiled by Suc (1984). This record shows that extremely dry conditions occurred in South-east France four more times before 1.2 Myr BP, which is the time of the glacial maximum. Suc (1984) suggested that the previous subtropical flora was decimated or thoroughly modified by the intensity and rapidity of these climatic changes, and that by the beginning of the Pleistocene, about 1.6 Myr B P, the basic elements and organization of the Mediterranean flora were in place, with minor dynamic modifications in the North during subsequent glacial surges.

This was the generally held view of the development of Mediterranean vegetation until Bertoldi et al. (1989) published results of a pollen study from Calabria and Sicily in the south central Mediterranean. Their cores from four sites cover the period from about $4.3 \mathrm{Myr} \mathrm{BP}$ until about 1.1 Myr вр. These data indicate the ubiquity, as early as 3.8 Myr BP, of scleriform evergreens and non-arboreal plants whose form and adaptations were similar to modern Mediterranean vegetation. Furthermore, pollen data from these sites at the South of the Tyrrhenian Sea show the onset at about 3.2 Myr BP of cooler, moister and less seasonal conditions. These conditions resulted in forests of Picea and Abies in Southern Italy, which lasted until about 2.4 Myr BP, when seasonally arid conditions returned. For this same time period, 3.2-2.4 Myr BP, the data of Suc (1984) showed drier and more seasonal conditions in the north-west Mediterranean. Since 2.4 Myr BP (the time of the onset of Northern hemisphere glaciation), the pollen data of Bertoldi et al. (1989) from south central Mediterranean sites show drought-adapted vegetation with little cyclic response to glacial surges, even at glacial highs when the Po valley hosted montane vegetation. These data show no significant taxonomic changes until the Pleistocene boundary about 1.6 Myr BP, when taxonomic composition at these and many other sites throughout the Mediterranean region underwent rapid change toward the modern species composition, although there is presently no evidence of major climatic change in the south central Mediterranean at this time. Oxygen isotope studies of the Tyrrhenian Sea floor (Thunell et al., 1990) and studies of micro- and nano-fossils of the Tyrrhenian Sea floor (Cita et al., 1990) present collateral evidence for these periods of change and no change in the climate of the south central Mediterranean.

All these studies show that, in the vicinity of the Mediterranean Sea, the modern Mediterranean climate and corresponding vegetation types did not develop at the same time nor in the same way in all areas where they presently exist. When climatic change makes it no longer possible for the species elements of the vegetation adapted to former conditions to persist, the evolutionary lines of these species either become locally extinct or they evolve into species capable of tolerating the new conditions. At least two factors would make the local extinction of formerly adapted species the more likely: a rapid rate of change in the climate; and the competitive presence of newly arrived species already welladapted to the new conditions. Suc (1984) suggests that the onset of arid conditions around 2.4 Myr BP in south-east France may have been so rapid that evolution of subtropical adapted species into arid adapted species in situ may have been unlikely; more likely would be the extinction of former species and their replacement by better adapted colonizers. The pollen data of Bertoldi et al. (1989) from south central Mediterranean show seasonally arid conditions from about 4 Myr BP, but rapid development of cooler climate beginning about 3.2 Myr BP. This caused the local extinction of drought-adapted species, which were replaced by colonizing spruce and fir. The same pollen data indicate the return of seasonal drought about 2.4 Myr B P, which brought the local demise of these trees and recolonization by species adapted to seasonal drought. This is coincident with the rapid advent of similar dry conditions in south-east France. It is plausible that, in addition to in situ evolution, colonization/extinction may have also played a role in the rapid taxonomic turnover of the Mediterranean vegetation beginning $1.6 \mathrm{Myr}$ в , which resulted in most of the present day Mediterranean flora, which seems to have been continuously present for about the past million years.

\section{EVALUATION OF VICARIANCE AND DISPERSAL HYPOTHESES}

In the case of plants, such as those in the G. ephedroides complex, that are adapted to the seasonal, arid summers typical of the south central Mediterranean since 2.4 Myr BP, land movement vicariance can be safely ruled out. Although the African plate has continued to encroach somewhat, the configuration of the Mediterranean sea floor has remained essentially unchanged during the past $4 \mathrm{Myr}$, as indicated by the unbroken sonic reflecting layer of evaporites laid down on the sea floor during the Messinian (Hsu, 1983).

Vicariance created by the refilling of the Mediterranean basin during the Messinian would also seem an inadequate 
explanation for the present disjunct range of the G. ephedroides complex, whether the Mediterranean refilled rapidly, as evidence suggests, or more slowly, because for a million or more years preceding 2.4 Myr BP seasonally dry adapted plants were probably excluded from the south central Mediterranean by the seasonless, cold and wet climate. It seems more likely that G. ephedroides relatives established there after the arrival of the seasonal drought to which it is adapted. Processes determining their current disjunct range would seem more likely to have operated since $2.4 \mathrm{Myr}$ B P, well after North Africa, Sardinia and Sicily/Italy had been separated by water, by which time some longer range dispersal would be necessary to establish plants on each of these three separate areas. The presence of this would not rule out that the three disjunct areas along the Sicily/Italy Tyrrhenian coast could be the result of range fragmentation.

How could dispersal be distinguished from vicariance by range fragmentation on the basis of other data? Fragmented populations that evolved in situ would show a pattern of geographical contiguity that was consistent with the fragmentation sequence, while populations established by dispersal and founding would not necessarily be even geographically contiguous. No geographical data were used to test the necessary compatibility conditions nor to reconstruct the diagram of historical contiguities of Fig. 2, so geographical data can be used as independent criteria to argue the differential plausibility of mechanisms. In the case of vicariance by the refilling of the Mediterranean, the sequence hypothesized to have created the disjunct populations of the $G$. ephedroides complex is known. A hypothetical widespread population (possibly $\mathrm{j}$ ) would split first into $h, i$ and all the rest; then $g$ would split from the rest; then a, b, c would split from d, e, f. But this is not the diagram of historical contiguities with which all the data are compatible. Even if we did not know the sequence of vicariant events, they would be expected to divide ranges into geographically contiguous pieces. Figure 2 shows that areas $b$ and $c$ on the Neapolitan coast of Italy are historically next to the Algerian coast. This conflict of historical and geographical contiguities makes it seem less likely that b, c was fragmented away from g, and more likely that b, c was founded by $\mathrm{g}$ through long distance dispersal.

A vicariance explanation requires that a newly evolved property completely replace its ancestral condition throughout the area in which it evolved before it fragments again. Such explanations become more plausible if a period of time sufficient for this replacement process has passed subsequent to each vicariance event, and if each event breaks a single formerly continuous range in two or at most a few pieces. Area a may have belonged to a continuous area extending down the Italian coast and across the northern coast of Sicily to include areas $\mathrm{d}$, e, $\mathrm{f}$ before the arrival of the colonizer of areas b, c and subsequently became fragmented away from them by the local extinction of plants along the Italian coast. This explanation is made more plausible by the fact that the area $a$ is an island, where the three novelties of a could have more easily spread through the extant population, after the fragmentation. But, this island was under water until about 1.8 Myr вP, so it could not have been included in a widespread area before then. On the other hand, if the elimination of the hypothesized plants from the Italian coast happened as part of the rapid turnover of vegetation at the beginning of the Pleistocene 1.6 Myr BP, then the population could have been there for a quarter of a million years before withstanding competition, avoiding habitat destruction, or in some other way surviving.

In summary, the comparative data of G. ephedroides are remarkably compatible. However, the disjunct distribution must have developed too recently for the vicariant events associated with the refilling of the Mediterranean Sea 5 Myr вP to explain anything, and the vicariance diagram that describes these events is not the same as the one specified by the data. Arguing against any vicariance process is the fact that the historically contiguous areas specified by the diagram with which the data are compatible are not also geographically contiguous. This would require that at least some dispersal be part of the explanation. Too recent vicariance, such as by habitat destruction following the arrival of human beings in the Tyrrhenian basin, would be unlikely to have left enough time for the very large amount of consistent betweenarea variability, as shown in Table 2 , to have evolved during the vicariance process. Clearly, an explanation based largely or entirely on contemporary dispersal and evolution over the past million years would seem more likely than any explanation requiring substantial vicariance.

\section{NEITHER VICARIANCE NOR DISPERSAL}

The comparative data satisfy remarkably well the necessary compatibility condition that enables us to reconstruct a pattern of historical contiguity. But how readily would other explanations predict such data? Other common historical processes result in a relationship between the geographical and the comparative data that do NOT meet the necessary conditions that are evidence of either dispersal or vicariance. Species that disperse abundantly and widely, and that readily establish new populations, are likely to become ubiquitous soon after new habitat is made available: evolutionary change as a consequence of small isolated populations would be less likely to occur during their colonization of new areas, new areas might be founded several times from different established areas, and newly colonized areas might coalesce and not remain disjunct. If evolutionary changes were not passed throughout the entire contiguous population before it fragmented again, or if the same changes occurred in different populations after they fragmented, or if properties were lost after fragmentation, then the sequence of historical fragmentation would be obscured. Similarly, if different founding events were followed by the same evolutionary change, or if the change following a founding event was the loss of a property that had evolved following an earlier founding event, then the founder relationship would be obscured in the comparative data. Repeated local extinctions and recolonizations, or coalescing of previously distinct regions, would result in a complicated history that could not 
be recovered by compatibility of comparative data. It seems plausible that such complicated distributional or fragmentational histories are the reality for many species of Mediterranean plants, as well as for other plants and animals. The relationships between their evolved properties and their locations would not be mostly compatible to indicate a single diagram of historical contiguity.

There are several possible reasons why the compatibility level of morphological data, indicating a single historical pattern, might be so high in the case of the G. ephedroides complex. The plants are fairly long-lived, do not establish easily, and may have very narrow habitat limitations. Their potential for evolutionary change may be balanced with their potential to colonize distant areas. Expanses of sea separate most areas, minimizing post-founding gene flow. Characters with high intra-site variation compared with among-site variation were eliminated from further consideration. This will eliminate some noisy or random characters, but does not rule out the possibility that similar novelties may have stably evolved independently at sites with different founders, which would have generated inconsistencies in the data. Of course, one possible explanation for very high levels of compatibility is that the pattern revealed may in fact be historically correct.

\section{DIRECTION OF FOUNDING}

The very high degree of consistency of the comparative data with mechanisms of evolutionary change during founding, together with considerations of other known aspects of the natural history of the Mediterranean basin, make the historical contiguities diagrammed in Fig. 2 seem a plausible if undirected depiction of founding events and not vicariance events. But we need to turn again to independent natural history data to estimate the direction in which these founding events took place.

Dispersal explanations could begin with hypothesizing a place for original founder. North Africa seems plausible because about 3.9 Myr, arid climatic conditions were extant in north Africa and may have remained so somewhere until 2.4 Myr вP when colonization of the south central Mediterranean by dry adapted species again became possible. In addition, the G. ephedroides complex is included in a section with a centre of diversity in north Africa. The hypothetical plants of kind $\mathrm{j}$ could have been established in Algeria with subsequent dispersal/founding to Sardinia and independently to Sicily. After these founding events in Sardinia and Sicily, there could have occurred seven evolutionary changes in the Algerian plants; then $c$ could have been founded by dispersal; all seven changes were carried to $c$ by the dispersal entity, as described above. However, plants of kind $\mathrm{j}$ need not have occurred in Algeria. Dispersal to Sardinia could have occurred from Algeria by a dispersal entity carrying some of the seven properties that distinguish $g$ from $\mathrm{j}$ and the rest could have evolved after the dispersal/founding of a population in Sardinia. In this case, $j$ would have evolved in Sardinia and founded a population on Sicily subsequently. Dispersal between $e$ and $f$ and between $h$ and $i$ was not followed by any evolutionary changes in the newly founded area. Thus we cannot tell whether $\mathrm{d}$ was founded from e or from $\mathrm{f}$. Two changes: longer calyx tube $3 \mathrm{C}$ and longer wing $14 \mathrm{~B}$ evolved in $\mathrm{d}$ and were then carried to area a by the dispersal entity. After area a was founded from d, its plants evolved smaller pollen and larger fruit.

Perhaps the G. ephedroides complex was well represented in the Tyrrhenian basin before 3.2 Myr BP, but went extinct there after the advent of cool wet weather. During this cool wet period members of the complex may have remained nearby in habitat with more arid conditions further south or west in Africa. Also, pollen data show a change about 3 Myr вP toward more arid conditions to the north and west of the Mediterranean. Where the gradient from the cool wet south central toward the dry north-west fell at that time in unknown. Members of the complex may have survived in south-east France or Corsica, and been the first to colonize the present areas of the G. ephedroides complex, when seasonal summer drought later returned to the south central Mediterranean. However, this seems less likely than an African origin because the G. ephedroides complex is not known from Corsica or France, and in northern Sardinia, populations form hybrids with populations of species outside the $G$. ephedroides complex suggesting that this contact may be relatively recent.

\section{AVAILABILITY OF DATA ANALYSIS TOOLS}

The data of Table 2 were analysed for the necessary compatibility condition using the computer program CLINCH (Fiala, 1984), which runs on PC under DOS. This and related programs are freely available for download from the author's web site: http://www-Personal.umich.edu/ $\sim$ gfred/. More recently, all the power of $\mathrm{CLINCH}$ plus other new and related powers have been implemented in SECANT for wiNDOws by Salisbury (1999). It is available at his web site: http://jkim.eeb.yale.edu/salisbur.

\section{ACKNOWLEDGMENTS}

I am grateful to my colleague and friend, Dr Giovanni De Marco, then of the Botany Institute of the University of Rome, whose botanical collections and measurements provide the morphological data of the example discussed here. With biogeographical questions in mind, he carefully conceived the plan under which specimens of the G. ephedroides complex were collected and measured. My compatibility analysis of these morphological data produced a result so clear that initially I was reluctant to believe it. When I became convinced that it was correct, we presented it in our 1985 publication in Italian. It is presented here again in Fig. 2. I am also grateful to Giovanni De Marco for his warm and generous acceptance of me as a stranger in Rome, Italy, in the mid 1980s. I am grateful to Charles N. Talley for producing the map and figures. I wish to thank the anonymous reviewers and several colleagues for their helpful suggestions, which improved earlier versions of this work. 


\section{REFERENCES}

Bertoldi, R., Domenico, R. \& Thunell, R. (1989) PliocenePleistocene vegetational and climatic evolution of the Southcentral Mediterranean. Paleogeography, Paleoclimatology, Paleoecology, 72, 263-275.

Cita, M.B., Santambrogio, S., Melillo, B. \& Rogate, F. (1990) Messinian Paleoenvironments: new evidence from the Tyrrhenian Sea. Proc. ODP Sci. Results, 107B, 211-228.

De Marco, G., Altieri, A. \& Estabrook, G.F. (1985) Relazioni evolutivi e biogeografiche dei popolamenti ad areale disgiunto di Genista ephedroides DC. Biogeographia, 11, 115-131.

Estabrook, G.F. (1984) Phylogenetic trees and character state trees. Cladistics (ed. T. Duncan and T.F. Stuessy), pp. 135151. Columbia University Press, New York, USA.

Estabrook, G.F. (1985) Historical biogeography: the relationship between phylogeny and geography. Biogeographia, 11, 37-47.

Estabrook, G.F. \& Meacham, C.A. (1980) How to determine the compatibility of undirected character state trees. Math. Bioscience, 46, 251-256.

Fiala, K.L. (1984) CLINCH, version 6.2; micro computer program and user's guide. University of Michigan Herbarium, Ann Arbor.

Hsu, K.J. (1973) Quando il Mediterraneo si dissecco. Le Scienze, 56, 19-29.

Hsu, K.J. (1977) The history of the Mediterranean salinity crisis. Nature, 267, 399-403.

Hsu, K.J. (1983) The Mediterranean was a desert. Princeton University Press, Princeton, NJ, USA.

Meacham, C.A. (1981) A probability measure for character compatibility. Math. Bioscience, 57, 1-18.

Meacham, C.A. \& Estabrook, G.F. (1985) Compatibility methods in systematics. Ann. Rev. Ecol. Syst., 16, 431-436.

Nelson, G. \& Platnick, N. (1981) Systematics and biogeography: cladistics and vicariance. Columbia University Press, NYC, USA.

Pokras, E.M. \& Mix, A.C. (1987) Earth's procession cycle and quaternary climatic change in tropical Africa. Nature, 326, 486-487.
Principi, P. (1942) Le Flore del Neogene. Pubbl. University of Studi Firenze. Fac. Agraria Forestale, Firenze, pp. 1-147.

Runemark, H. (1970) The role of small populations for the differentiation in plants. Taxon, 19, 196-201.

Salisbury, B.A. (1999) Strongest evidence in compatibility: clique and tree evaluation using apparent phylogenetic signal. Taxon, 48, 755-766.

Spach, E. (1845) Revisio Generis Genista. Ann Sci. Nat. Ser., 3, 102-158.

Suc, J.P. (1984) Origin and evolution of the Mediterranean vegetation and climate in Europe. Nature, 307, 429-432.

Thunell, R.C. \& Williams, D. (1983) The stepwise development of Pliocene-Pleistocene paleoclimatic and paleoceanographic conditions in the Mediterranean: oxygen isotope studies of DSDP sites 125 and 132. Utrecht Paleontol. Bull., 30, 111-127.

Thunell, R.C., Williams, D., Tappa, E., Rio, D. \& Raffi, I. (1990) Pliocene-Pleistocene stable isotope record for ODP site 653, Tyrrhenian Sea: implications for the paleoenvironmental history of the Mediterranean. Proc. ODP Sci. Results, 107B, 211-228.

\section{BIOSKETCH}

George Frederick Estabrook is Professor of Botany in the University of Michigan, Ann Arbor, MI, USA, and Research Scientist in the University of Michigan Herbarium. His research interests are in the application of ecological methods in ethnobotanical studies (Ethnobio$\operatorname{logy} 18: 15-33,1998)$, and in the development of computational methods for application more generally to studies of ecology and evolution (J. Ecology 86: 983-988, 1998). For the past several years he has applied ecology to elucidate the relation between the culture and the technology of subsistence peasants in interior Portugal. 